\title{
DCM 4.0: Integration of Industry 4.0 and Demand Chain in Global Manufacturing
}

\author{
Elmira Naghi Ganji \\ Applied Engineering and Management \\ Faculty of Engineering \& Science, University of Greenwich \\ Chatham, United Kingdom \\ e.naghiganji@gre.ac.uk
}

\section{Satya Shah}

Applied Engineering and Management

Faculty of Engineering \& Science, University of Greenwich

Chatham, United Kingdom

s.shah@gre.ac.uk

\begin{abstract}
Technological advances are constantly driving dramatic increase in effective sharing of information and material among the supply chain entities, since the development of industrial changes. Living in early decades of 21th century, the fourth industrial revolution has been emerged called "Industry 4.0", being a hot topic for academic discussions. On the other side, demand chain management (DCM) is being highly considered as a transformed version of supply chain, looking the business chains through a customer-centric lens and aiming towards making pulls for new products in contrast to supply chain strategies. This paper seeks to explore the opportunities for expansion of Industry 4.0 within the context of demand-driven supply chains, due to the expected implications in this field. Reviewing the existing literature and industrial challenges, authors tend to shed some lights on the advantageous linkage between Industry 4.0 and demand chain, introducing a new concept called DCM 4.0. The results and findings would be utilized by scholars and practitioners aiming to discover the interrelationships within the same field.
\end{abstract}

Keywords-Supply chain manegement ; Demand chain management (DCM); Global Manufacturing; Industry 4.0; Internet of things (IoT)

\section{INTRODUCTION}

Customer satisfaction is now the key component for confirming the survival of all the competitive business environments. As part of the supply chain structure, customers and end-users are usually been considered as a downstream view locating within the last stage of the distribution networks. However, since early 2000's, researchers and scholars started to begin a new era on supply chains, exerting more power on customers rather than suppliers and manufacturers $[1,2,3]$. This approach resulted in emergence of "Demand Chain" concept which tends to create pull and attraction for new products. This can be interpreted that the new products would not be developed and manufactured, unless there are either definite customers willing to purchase them or customers get involved in development projects in any for. This practice can even start

\author{
Alec Coutroubis \\ Applied Engineering and Management \\ Faculty of Engineering \& Science, University of Greenwich \\ Chatham, United Kingdom \\ a.d.coutroubis@gre.ac.uk
}

within the very early stages of the new product development (NPD) processes such as design stage, in which many companies are now providing with the opportunity for the customers to contribute within creating, designing and ordering their own desired products, help companies for increasing their market volatility, shortening the product lifecycles and logistics costs remarkably. Similarly, Industry 4.0 is launched by Germans in 2011, introducing the idea of a fully integrated technological advancement. Being famous as fourth industrial revolution, Industry 4.0 is also revolutionizing the traditional supply chain ecosystems moving them towards creation of value chains which are more connected, smart, highly efficient eco-systems and more customer-friendly. As evident, according to statistics in 2014, Industry 4.0 investments along the value chain was highly considered within supply chain, Product development/engineering and planning by $57 \%, 56 \%$ and $52 \%$ respectively (Pwc.de). This shows the necessity for exploring the crucial role of Industry 4.0 and its different dimensions in supply chain, and especially within its transformed version of DCM.

\section{LITERATURE REVIEW}

\section{A. A Prelude to Demand Chain Management (DCM)}

The transformation of traditional supply chain management began in parallel with the introduction of TOYOTA's Kanban systems in 1950's, the pull-based production systems. The very first concepts within demand chain criteria include just-in-time (JIT) production, electronic data interchange system (EDI), barcodes and point-of-sale (POS) during 1980 and 90's [4]. The main goal of all the new introduces practices was improvement of supply chain efficiency, reduction of lead time and inventories as well as smooth flow of information and materials along the supply chain operations. A very robust incentive for such shift was the improved globalisation in late 2000's and the rising number of selective customers who started to become difficult to get satisfied by "one size fits all" strategy of manufacturing companies [5]. Customers are also got used 
towards more convenience and personalized products. Consequently, some dominant product-based companies such as Procter \& Gamble and Walmart also started to shift their strategies towards demand practices in order to gain competitive advantage and survive within the new market conditions and customer needs' fluctuations [6]. Such demand-driven practices are so wide across the organisational operations from product development to marketing, sales, distribution and logistics systems [2, 7]. Hence, the question is that how organisations could distinct between the demand-driven chain and the conventional supply chain, due to the fact that end-users and demand chain in still part of the supply chain as last stage. The answer might be that, supply-driven and demand-driven difference is in the vision, attitudes and the strategies of organisations, meaning that the supply chain strategies start with suppliers having a purchasing focused view, while a typical demand-driven chain is based on customer requirements moving upstream in SC. In other words, a supply-driven entity tries to push new products into the market, while demand-driven SC attempts to make products and goods for its particular customers, meaning that the products would be pulled by those customers and in this way, the success of NPD would increase and even get confirmed.

According to the review of literature and industrial challenges within this field, two different interpretations can be presented for better understanding of DCM nature. Firstly, the role of marketing within DCM can be highlighted, due to the fact that marketing acts as a borderline between DCM and SCM in order to bridge the interrelationships between them $[8,9]$. This means that innovative marketing practices such as postponement, mass customization and collective customer commitment can be employed as a strategic tool to prevent the risks and failures associated with NPD programmes [10].Companies such as BMW, 3M, Yamaha, Threadless and Muji have begun applying those approaches since last decade by involving customers from the very beginning of the design, development and manufacturing processes utilising technology infrastructures. In this case, collective customer commitment is an inclusive form of the former ones that customers are asked for early purchasing before the final development and production, therefore, getting committed for buying their desired products. Undoubtedly, this necessitates for the companies to create a special knowledge and trust to customers regarding this innovative practices [10].

Secondly, the application of technology platforms have been highlighted as a very crucial factor within implementation of DCM practices. This is referred as an element to provide with real-time information on demand and inventory levels as well as tracking the ongoing material flow for all the supply chain components in order to effectively react to the unexpected fluctuations, which finally leads to reduction of lead time [6]. In this case, a key enabler is the dramatic improvements in processing speed, computing power and storage capabilities through external infrastructures and cloud-based systems which can further support the prompt, frequent and data-intensive processes across DCM. Meanwhile, six critical factors are pointed out for the success of demand-driven chains comprising of, choosing the right technology platform, revisit data collection and analysis, rethink operations (e.g. production capabilities, logistics, procurement), identify goals and motivations, management of costs and service trade-offs as well as changing the organization and staff behaviour. Authors also state that demand-driven chain is based on four key pillars including visibility (of demand and inventory levels), infrastructure (to quickly adopt to the short-term changes), coordination (among all company entities) and optimization (of overall supply chain performance) [6]. The following figure indicates the comparison between operations of a traditional supply chains and a demand-driven supply chain (DDSC). As it is obvious, by use of IT platforms, rapid information sharing reduces the information sharing from 48 days to Zero across the distribution network entities. This also accelerates the material flow, benefiting the material suppliers by reduction of inventory, transportation costs, operations' planning time, warehousing costs and lost sales. It is claimed that DDSC has got the potential to strongly benefit the end-users by improving customer sell-through and satisfaction. In spite of all the mentioned benefits of the revolutionized supply chain, it is still in its very early stages of development, which needs top management commitment and support, identification of target market and customer values.

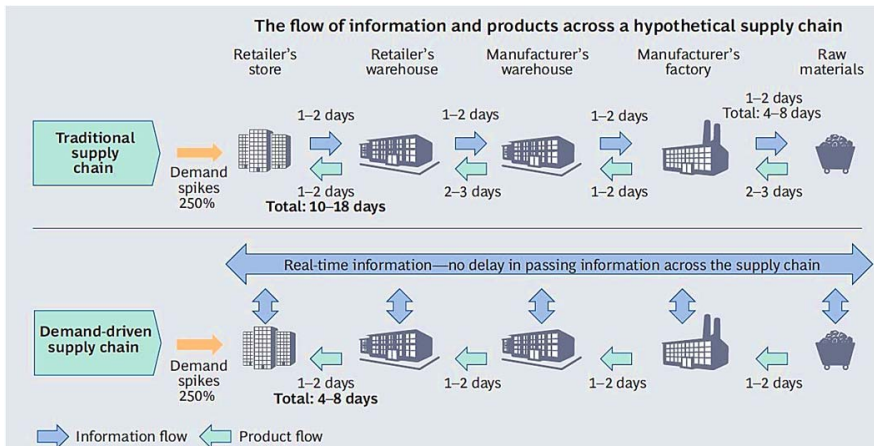

Figure 1. DCMs enable supply chain participants to share information and products more rapidly and frequently [6].

Both highlighted perspectives are being applied by some world leading companies such as Zara (Spanish fashion apparel). Zara is now adopting a combination of both viewpoints. Starting with market research, Zara is basically targeting 17-22 years old customer with low budgets. Besides, the lead time has reduced to 2 weeks from initiating the sketch design to product availability in market. The personal digital assistant (PDA) devices are being used in Zara stores in order to send Inditex HQ all the information regarding sales trends and customers' impressions, reactions, ordering needs and feedbacks [9]. Likewise, Google has started to adapt identical strategies for increase of market 
responsiveness, by working on the project of "fleet of drones" to serve as delivery machines to ship consumer goods and medical goods to remote residential areas [11]. Hence, these companies are practicing the customer-focused practices leading to increase of profitability, product availability, and market responsiveness and delivery accuracy. This is only possible mainly with the help of effective association between the triangle of SCM, DCM and marketing, where restrategizing of four "P"s of marketing plays a vital role [9].

\section{B. Principles of Industry 4.0 (SRS)}

The principles of industry 4.0 emerged from the strategic development in Germany that was aiming at the creation of more smart and intelligent factories (i.e. smart factories) through the transformation of manufacturing technologies with cyber physical systems (CPS), Internet of things (IoT), Big Data Analytics (BDA) and Cloud Computing. It is being suggested that within industry 4.0 dimension, these manufacturing systems can monitor physical processes that allows and enables the smart decision-making activities in real time through multiple channels of communication and cooperation between humans, machines and technologies.

Research studies define I4.0 as the combination of integrated production and manufacturing technologies to that of intelligent and smart systems addressing the needs of the changing market demands and overall business models through value and demand chain management practices. The use of advanced manufacturing, information and production technologies is termed as intelligent manufacturing. These systems allow any physical process and the flow of information to be available within the manufacturing and supply chain process in the industry including larger organisations and that of SMEs. This intelligent manufacturing systems requires specific technologies that enables multiple devices and systems to be able to integrate and function according to the requirements and its historical interactions within the environments. To allow more directive and prompt decisions the intelligent technologies enables direct communication with the entire manufacturing system with the use of more established artificial intelligence (AI) within their systems, thus allowing systems to observe and learn from its experiences within the connected and smart practices of the industry [12].

Many research studies highlights the importance of long time period of development for any industry 4.0 implementation and focusses towards four key aspects within any manufacturing area as shown in figure 2 . The first aspect is that of the factory or in this instance as "smart factory" that involves a more integrative approach where all manufacturing resources exchange information and knowledge collectively between the partners. It also allows manufacturing processes including design, planning, production and services to be simulated and connected closely to be controlled and operated interdependently. Hence, similar research studies refers to this level of factory operations as "smart factories" [13].

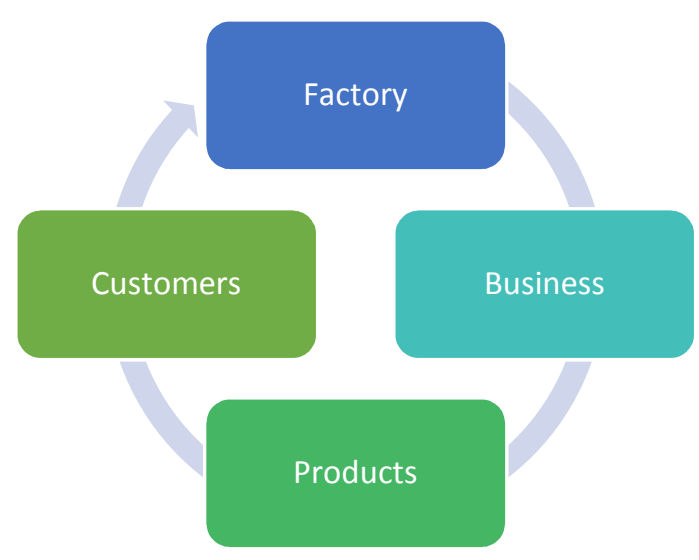

Figure 2. Industry 4.0 and future manufacturing visions

Secondly, a more centralised communication tool that will support the entire business function, including departments, operations, supplier networks, resources, customers and others in one centralised manner. Each of this centralised unit will be real time and operate on the demands of the other links within the unit allowing to share resources between all the units together. Hence, most of the future business networks and organisations within industry 4.0 will tend to operate under such centralised and cooperative networks (i.e. links) and will enable the sharing of the inputs in real time while sharing unified resources between themselves. Thirdly, while considering the environment and that of the business focus, the products manufactured within these factories ought to be smarter. Many of these products are equipped with sensors and parts which are identifiable, allowing to carry information and knowledge about these products and share with customers within the environment. This enables the manufacturing and design engineers to further enhance and improve upon the functionalities of the products while simplifying the products itself. For example, the measure of the state of product and that of its users, the specification information will further enable the better development and implementation of the products through all the stages of production. Finally, the forth aspect is that of the customers who will benefit from the implementation of Industry 4.0.

The development will lead towards more advanced purchasing and buying systems to allow and enable customers to order any function of the product with multiple variations within the product. It also allows the customers to change orders and implement new ideas and innovation during any stage of planning or production process. Similarly, the benefit of having smart products allows the customers to receive updates on the product development and that towards the utilisation of the products depending upon the specification and functionalities of the products itself. Hence, the use of industry 4.0 principles tends to propose a new change in direction towards the entire manufacturing and product development process [13]. 


\section{Indusry 4.0 Integration with Demand Chain Practices}

As highlighted within previous sections, the applications of IT-based platforms are getting widespread and viral within different supply chain functions. Being more specific, these platforms can be further by manufacturing organizations to help them embrace the sustainability as well as DDSC and transformation of customer relationships. Such practices vary depending on the elements that needs to be improved. For instance, in order for sustainable product design approaches, Industry 4.0, additive manufacturing (AM), autonomous robots and mass customization (MC) are getting attention towards optimization of manufacturing processes and operations as well as minimizing the environmental impacts [14]. Even beyond, Industry 4.0 is now getting popular due to the fact that it contributes for creation of value chain in a wider picture of supply chain, trying to add value to products and services [15]. Authors have also claimed that digitization is making supply chain to become more efficient, agile and customer-oriented

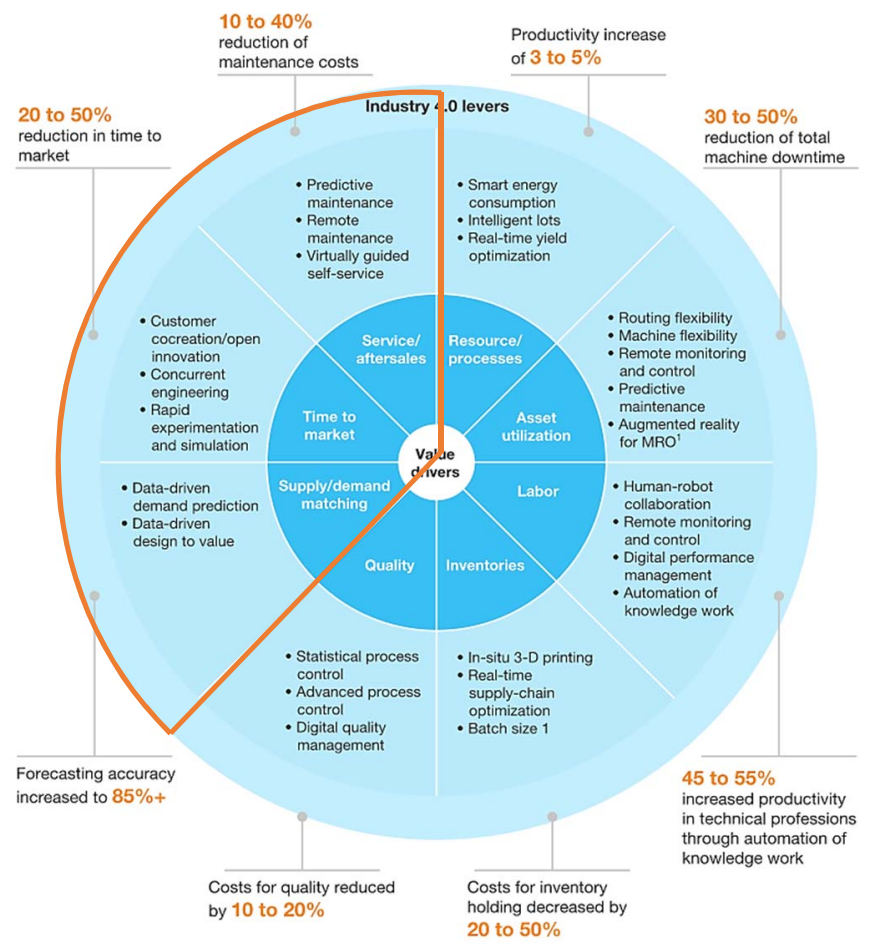

Figure 3. Industry 4.0 and its value drivers for customer involvement [15]

Figure 3 illustrates the wide range of involvement of Industry 4.0 as well as its value drivers for end-users of demand chain as highlighted in orange [15]. The ultimate purpose of Industry 4.0 value creations is also in line with the conceptual framework suggested for sustainable demand chain management (SDCM) [16] and this can be interpreted that customers are currently being considered as a center point within supply chain unites.

A comprehensive study has underlined the influences of advanced digital technologies such as Industry 4.0 on significant involvement of customers [17]. Authors believe that companies need to apply industry 4.0 technologies to their current customer relationship practices in order to transform from the traditional manufacturing practices towards the term called "digital manufacturing enterprise" (DME) introduced by them with the purpose of efficient flow of processes across the value chain. The following tables indicates the main differences between conventional/traditional manufacturers and the DMEs facilitated by Industry 4.0-enabled technologies. In a nutshell, the key differences between the two include, the audience they engage, the connection level they maintain and the monetization of products and services they provide with [17].

\begin{tabular}{|c|c|c|c|c|}
\hline & $\begin{array}{c}\text { Customer } \\
\text { experience }\end{array}$ & $\begin{array}{l}\text { Frequency of } \\
\text { interactions }\end{array}$ & $\begin{array}{c}\text { Context of } \\
\text { interactions }\end{array}$ & Value \\
\hline $\begin{array}{c}\text { Traditional } \\
\text { manufacturers }\end{array}$ & $\begin{array}{l}\text { Reactive: React to a } \\
\text { customer or partner } \\
\text { need, complaint, or } \\
\text { request }\end{array}$ & $\begin{array}{l}\text { Little to none: } \\
\text { None during use, } \\
\text { and infrequent } \\
\text { interactions for sales } \\
\text { and service }\end{array}$ & $\begin{array}{l}\text { Standard: } \\
\text { Interactions reflect } \\
\text { order history and } \\
\text { commany type }\end{array}$ & $\begin{array}{l}\text { Product: Value } \\
\text { derived from product } \\
\text { features }\end{array}$ \\
\hline Leading DMEs & $\begin{array}{l}\text { Proactive: Create } \\
\text { intentionally } \\
\text { designed } \\
\text { experiences that } \\
\text { guide customers } \\
\text { and partners based } \\
\text { on an intimate } \\
\text { understanding of } \\
\text { their situation }\end{array}$ & $\begin{array}{l}\text { Continuous: } \\
\text { Ongoing dialogue } \\
\text { enabled by digital } \\
\text { connection }\end{array}$ & $\begin{array}{l}\text { Customized: } \\
\text { Interactions reflect } \\
\text { the customer/ } \\
\text { partner's role, } \\
\text { relationship with } \\
\text { the brand, state } \\
\text { in the buying } \\
\text { cycle, location, } \\
\text { environment, and } \\
\text { other context } \\
\text { provided by the } \\
\text { physical-digital } \\
\text { connection }\end{array}$ & $\begin{array}{l}\text { Services/data: } \\
\text { Value shifts from } \\
\text { product features to } \\
\text { the analytics-enabled } \\
\text { insights derived from } \\
\text { the physical product } \\
\text { in operation }\end{array}$ \\
\hline
\end{tabular}

Figure 4. Additional attributes of DME customer interactions [17].

In terms of audience engagement, the DMEs expand their targeted stakeholders within the supply chain, from manufacturers as technology buyers to the customers who have interaction with the manufactures. This means that all the stakeholders need to be evaluated and influence through the new product development processes. This leads to enhanced customer loyalty and of course remarkable cost savings for the companies. In terms of connection, DMEs utilise the smart tools in order to identify the product performance and customer physical and digital interactions. Monetization is also currently being more considered, since companies are try to earn revenues by monetization of data and uncovering new ways to gain added insight. These companies are wide ranging in different sectors such as, travel, leisure, hospitality, automotive and banking [17].

In order to better understand the customer relationship within DMEs, the following framework is designed (Figure 5). Within discover and shop stage, technologies such as artificial intelligence, augmented reality and virtual reality (AR/VR), and online to offline intelligence can be used. As an example, Chevy automotive company is using a website in order to evaluate customer's positivity on social networking websites to link them with customer top three personal characters in order to increase their affinity and further interest for purchasing new cars. Within the buy and install stage, digital technologies such as partner relationship management (PRM) platforms, RFID, GPS and predictive analytics are currently being used. For instance, an enterprise software company enhances partners and customer visibilities by providing with a 360 -degree for them including 
product documentation and knowledge, Multilanguage support for international use, customizable portal being accessible through mobile phones or desktops.

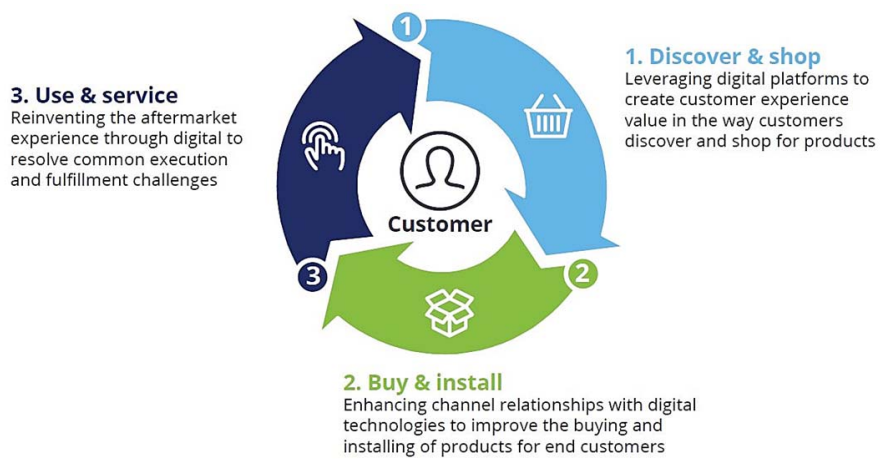

Figure 5. The customer life-cycle framework covered by Industry 4.0 [17].

Within aftermarket fulfilment or use and service stage, the customer satisfaction is estimated by $10-15 \%$ only and hence, technologies such as intelligent products are being utilised by many manufacturers. Intelligent products are in charge of creation of digital exhaust which is a stream of information including usage data such as cycles, speed, and up-time and product characteristics. These products are containing connected devices and pervasive sensing that can be monitored regarding their performance analysis. Other technologies such as $3 \mathrm{D}$ printing are facilitating the spare parts production particularly for remote production sites. $\mathrm{CNH}$ Industrial company manufacturing wide range of advanced products is now using connectivity and cloud platform to enable remote monitoring of the product's condition, operation and external environment in order to facilitate proactive maintenance and performance [17].

\section{Roles of IoT within Demand Chain Management (SRS)}

The role and concept of the Internet of Things (IoT) was first coined by British entrepreneur named Kevin Ashton with the idea formed during 1999 that described a system which the material world communicated with computers through sensors. During the late 2010 many of the devices that were connected to the network were higher than world's total population. This was later referred by many researchers as the internet of everything, through which systems were created for objects and processes, data, people and all other aspects defined as variables [18]. Research studies identified the most important features of IoT as context, presence and optimisation. Context mainly referred towards the possibility of any advanced object interacting within an existing environment and the response towards change. The key characteristics allowed objects to facilitate information including physical and atmospheric condition alongside location of the objects. Similarly, presence or omni-presence provided objects as connections to user defined networks and that they will communicate with each other in the future. Finally, optimisation focussed towards the functionality of every object. Some of the key application areas of IoT within the supply chain management areas are as follows.

- Production and Supply Chain Control - smarter production measures and solutions are very applicable within all manufacturing environments; including production lines, management and inspection areas; as well as control towards production values and targets;

- Transportation and Logistics Management - many of major issues including location and control measures of the transportation of goods and products could be carried out more effective using smarter transportation measures and technologies such as IoT and Big Data Analytics applications;

- Sustainable and Environmental Systems - that enables the use and practices of management of key resources towards more safe operation of the resources such as that of water and nature resources used within the overall manufacturing production environments;

- Intelligent Energy Systems - this intelligent energy systems will facilitate several advanced solutions that enables the management and appropriate use of utilities and resources; that includes the consumption during the process and production usage within the manufacturing environments.

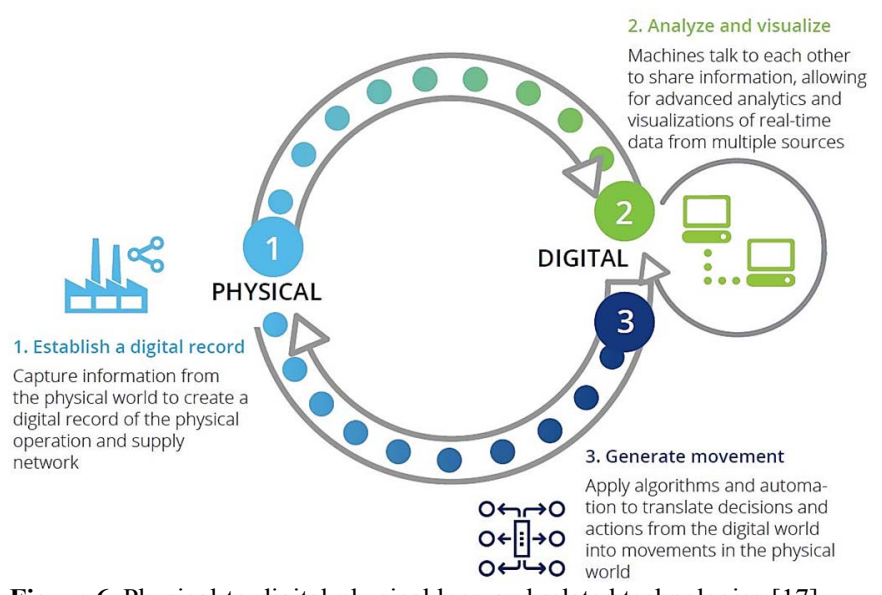

Figure 6. Physical-to-digital-physical loop and related technologies [17].

The most vital role of Industry 4.0 is to combine the IoT with related digital and physical technologies such as AM, autonomous robots, artificial intelligence, analytics and high performance computing. The main aim of this interrelations is to gather digital information from several parties of the supply chain and act as driving factors towards physical manufacturing of products. In other words, IoT based technologies are Industry 4.0 facilitators of physical material production by means of physical-to-digital and digital-tophysical loops. Figure 6 illustrates the information value loop (IVL) considering the association between Industry 4.0 and IoT roles. Therefore, IoT makes a source of value out of objects and transforms the supply chains and manufacturing processes to become smarter. It can be interpreted that the 
IoT act a nutshell of Industry 4.0 creating a global integration between customers, manufacturing products and machines. By doing so, the physical objects within the real world would be linked to virtual manufacturing environments. Moreover, digitization of products and services are acting as a key driver of industrial solutions which can ensure competitiveness and increasing revenues of company by $2-3 \%$ per year [17]. IoT and "ordinary" internet are also distinguished within the literature, since the nerve ends of internet are invisible, lowend and low energy consumption, while the nerve ends of internet are full-scale computers [19].

Numerous devices are connected to the IoT, fact that proves the emerging IoT phenomenon to be promising and dominating in many fields, offering new business opportunities. Researcher were inspired by the well - known Western Union's story and its lessons to the industry world, approaches the "Internet of Everything" or "Internet of Connected Objects" (ICO) as a socio - technical phenomenon [20]. It is believed that it can influence positively existing companies, markets and the entrepreneurs to embrace innovative ideas that it offers. IoT is a network which interacts with different types of environment. The physical environment includes human and non - human objects linked through a wireless network which furthers their communication. The technological environment consists of software, hardware, technologies, data and special platforms that help objects' interactions in the physical one. A broader socioeconomic perspective includes many factors and players such as business leaders, technical or legal requirements and associations which protect consumer's privacy, who is the main target by the entrepreneurs through the IoT use, being also the most significant element in the socioeconomic environment [20].

\section{RECOMMENDATIONS AND FUTURE RESEARCH}

The paper presents an overview of industry 4.0 and its implications within the demand chain management that aims to transform the supply chain and business processes. Some of the future research work within this area should aim to focus towards the development of novel framework towards intelligent manufacturing and data driven systems to provide the linkage on industry 4.0 and that of the demand chain. As evident from multiple research studies the integration and development of industry 4.0, a more applicable and advanced framework towards demand focussed and integrated manufacturing system is important. This advanced framework will cover many areas that are to be used within multiple enterprise networks and hence the implementation of demand-intelligent manufacturing systems is more applicable within the given situations. Typical technological applications such as wireless communication systems, data analytics and big data models and IoT technologies will be heavily focussed within the framework to allow a more robust and effective demand-intelligent systems to facilitate the supply chain environments.
The authors of the paper has also identified that in order to implement more intelligent and smart manufacturing techniques and practices, existing platforms and systems needs to be advanced and requires level of modifications within the existing infrastructure of the manufacturing environments. Technologies such as smart networks, Internet of Things (IoT), virtualisation and digitisation, service level technologies and smart technologies and tracking devices will be of key importance due to the increasing demands and requirements from the customers towards more customised products. This will further increase the demands and expectations and the overall cost of manufacturing of products. One such aspect could be covered through platform technology that enables the reduction of cost through full usage of flexible and reconfigurable manufacturing systems through smart and intelligent design, planning, production, logistics and supply chain management features. Similarly, multiple platform technologies focuses to provide more novel solutions to address more complex and customised products within the design and development stages. This would also act as a driving factor for transformation of supply chain concepts moving towards adoption of the demand-driven supply chain principles within the near future.

Secondly, through our paper and literature investigation it has been seen that smart manufacturing is to be considered as an important future aspect from both research and application aspect as it enables the added value provision to many product functionalities through the use of advanced and intelligent use of technologies compared to traditional manufacturing methods. Finally, open and innovative framework is required to enable the integration of collaborative efforts within manufacturing for any downstream and upstream activities. Hence, one of the key focus area for any future study should not just be focused towards product based environments, but also towards service oriented concepts towards intelligent and smart manufacturing, thus adding in as the key component towards industry 4.0 concepts.

The paper also identified that there is huge gap between recent industry applications to that of the enhancements of industry 4.0. Many of current businesses including suppliers and logistical companies are more focussed towards implementation of product and technological innovation within their environments. Businesses are focussed towards the creation of value for their customer who is more informed and hugely demanding in the market place. The requirement of more customised and customer centric environment where increased emphasis is towards customer requirements relating to lead time deliver services, product availabilities and reliability. This is well achievable and possible through the introduction of new technological advancements such as Internet of Things, Big Data and Cyber physical systems that enables industry 4.0 to create opportunities that explores and meets the demands of the customers and wider contribution towards the demand chain management principles. 
It has been seen that many of the advances in technologies are driven by the increased demands of effective information and material (i.e. resources) sharing between different entities of supply chain throughout the industrial revolutions. Our paper has focussed to examine and evaluate the understanding covering the areas of the fourth industrial revolution (industry 4.0) through the context of supply chain management. While supply and demand are always considered as the important aspect of any manufacturing environment, more recently the prospect of demand chain management (DCM) has highly been considered as a transformed version of supply chain that examines the business activities through a customer centric aspect as pull strategy of products rather than push principles. This research study aimed to investigate the expansion of industry 4.0 within the context of demand driven supply chain environments. This research paper through the review of existing literature and that of challenges within the industry has aimed to provide the linkage of industry 4.0 and its technologies to that of demand chain and thus introducing the DCM 4.0 concept as knowledge framework. The findings and results of this paper further allows researchers and practitioners within the same field to investigate and link the developments further.

This research study presented through existing literature providing the findings that there is wider emphasis towards industry 4.0 as intelligent and smart manufacturing is becoming more important within the advancement of modern industry and economy. Future research and applications are highlighted after a systematic review. It is our hope that this paper can inform and inspire researchers and industrial practitioners to contribute in advancing the manufacturing industry forward. We also hope that the concepts discussed in this paper will spark new ideas in the effort to realize the much-anticipated Fourth Industrial Revolution.

Acknowledgements This paper is part of an ongoing research project within the research centre and includes a preliminary study towards discovering the linkages of industry 4.0 and demand chain management as concept towards an integrated DCM 4.0 concepts. The methodology is based on the literature review studies in order to highlight the current state of the main concepts within the context. As part of the literature studies, an overview of industry 4.0 in context of supply and demand chain management is examined and discussed within this paper. The research is further aimed to utilise a knowledge framework that will enable the linkage of industry 4.0 and its technologies towards the betterment of demand chain management practices within global manufacturing environments.
[1] M. Rainbird, "Demand and supply chains: the value catalyst," International Journal of Physical Distribution \& Logistics Management, 34(3/4), pp.230-250, 2004.

[2] U. Jüttner, M. Christopher, and S. Baker, "Demand chain managementintegrating marketing and supply chain management," Industrial Marketing Management, 36(3), pp.377-392, 2007.

[3] P. Hilletofth, and D. Eriksson, "Coordinating new product development with supply chain management," Industrial Management \& Data Systems, 111(2), pp. 264-281, 2011.

[4] T. Ohno, Toyota Production System: Beyond Large-Scale Production, Productivity Press, New York, NY, 2012.

[5] Y. Ye, and K.H. Lau, "Designing a demand chain management framework under dynamic uncertainty: An exploratory study of the Chinese fashion apparel industry," Asia Pacific Journal of Marketing and Logistics, 30(1), pp.198-234, 2018.

[6] J. Budd, C. Knizek, and B. Tevelson, The Demand-Driven Supply Chain, Making it Work and Delivering Results. [Online] Boston Consulting Group. Available at: $<$ https://www.bcg.com/documents/file106861.pdf> [Accessed 20 Feb 2018], 2012.

[7] J. Gattorna, Dynamic Supply Chains, Pearson Education Limited, London, 2015.

[8] G.S. Day, (1992) "Marketing's contribution to the strategy dialogue," Journal of the Academy of Marketing Science, 20(4), pp.323-329, 1992.

[9] P.M. Madhani, "Enhancing Competitiveness: Moving from Supply Chain to Demand Chain Management," Materials Management Review, 12(4), pp.16-19, 2016.

[10] S. Ogawa, and F.T. Piller, "Reducing the risks of new product development," MIT Sloan management review, 47(2), pp. 65, 2006.

[11] KPMG International, Demand-driven supply chain 2.0: A direct link to profitability. [Online] KPMG International. Available at: $<$ https://assets.kpmg.com/content/dam/kpmg/pdf/2016/05/demanddriven-supply-chain.pdf $>$ [Accessed 19 Jan 2018], 2016.

[12] R.Y. Zhong, X. Xu, E. Klotz, and S.T. Newman, "Intelligent Manufacturing in the Context of Industry 4.0: A Review," Engineering, 3(5), pp.616-630, 2017

[13] J., Qin, Y. Liu, and R., Grosvenor, "A categorical framework of manufacturing for industry 4.0 and beyond," Procedia Cirp, 52, pp.173-178, 2016.

[14] S. Erol, "Where is the Green in Industry 4.0? or How Information Systems can play a role in creating Intelligent and Sustainable Production Systems of the Future," 2016.

[15] P. Cayler, K. Naik, and O. Noterdaeme, [Online] Available at: https://www.mckinsey.com/business-functions/digital-mckinsey/ourinsights/digital-in-industry-from-buzzword-to-value-creation [Accessed: 20th Feb 2018], 2016.

[16] C.A. Vural, "Sustainable demand chain management: An alternative perspective for sustainability in the supply chain," Procedia - Social and Behavioral Sciences, 207, pp.262-273, 2015.

[17] J. Hood, A, Brady, R. Dhanasri, Business models will drive the future of autonomous vehicles, Deloitte university Press. [Online] Available at:

https://www2.deloitte.com/content/dam/Deloitte/cn/Documents/cip/d eloitte-cn-cip-industry-4-0-engages-customer-en-170224.pdf [Accessed: 20th Feb 2018], 2016.

[18] K. Witkowski, "Internet of Things, Big Data, Industry 4.0-Innovative Solutions in Logistics and Supply Chains Management," Procedia Engineering, 182, pp.763-769, 2017.

[19] E. Fleisch, "What Is the Internet of Things? An Economic Perspective," (White Paper), Swiss Federal Institute of Technology in Zurich/University of St. Gallen, 2010.

[20] V. Krotov, "The Internet of Things and new business opportunities," Business Horizons, 60, pp.831-841, 2017. 